\title{
Analyzing Dependence Structure of Equity, Bond and Money Markets by Using Time-Varying Copulas
}

\author{
Cuong Nguyen ${ }^{1} \&$ Tristan Nguyen ${ }^{2}$ \\ ${ }^{1}$ Department of Accounting, Economics and Finance, Lincoln University, New Zealand \\ ${ }^{2}$ Department of Finance and Accounting, Fresenius University, Munich, Germany \\ Correspondence: Tristan Nguyen, Fresenius University, Infanteriestr. 11a, 80797 Munich, Germany. Tel: \\ 49-892-0003-7353. E-mail: Tristan.Nguyen@hs-fresenius.de
}

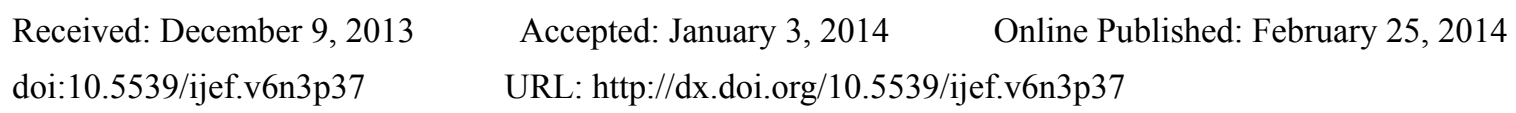

\begin{abstract}
In this essay, we analyze the dependence structures of equity, bond and money markets in Australia, the United States as well as the linkages between the two countries. The dependence structures have become more important for investors, risk managers and regulatory policy makers during the current period of financial crisis. Especially investors should be aware of the dependence structures which show the co-movement patterns between different markets in order to diversify and reduce the risks of their portfolios. To capture the structure linkages between different markets, we propose the combination of empirical distributions and time- varying copula models. Furthermore, we show an effective and informative way to analyze dependence between variables, especially to provide a better understanding of the co-movements of financial variables as well as the risks associated with dependence structures among them. The empirical findings provide some important implications of a wide range of areas related to investment in Australian and US financial markets.
\end{abstract}

Keywords: Australian futures markets, dependence structure, copula, the US futures markets, time-varying copula

\section{Introduction}

Further understanding of linkages and interactions across financial markets is of vital importance to investors involved in international investment markets and is an indispensable consideration of policy makers since financial markets worldwide have become more and more integrated. There appears to be a strong correlation between financial markets and crises, for instance, if a crisis occurs in the US, this is followed by a crisis in Asia or Europe. This can be seen after several crises all over the world, such as the 1987 stock market crash or the 1997-1998 Asian financial crises and especially the most recently sub-prime mortgage crisis in the US in 2008. Thus, there has been an extensive body of literature devoted to the examination of linkages between financial markets, especially the linkages between the equity, bond and money markets.

Fleming et al. (1998) analyzed the nature of volatility dependence structure between the stock, bond and money markets in the US by using a multivariate speculative trading model which formalizes the linkages between information and volatility. The paper showed the increasingly strong volatility dependence structure between stock, bond and money markets especially after the stock market crisis in 1987. Kim et al. (2001) used a multivariate Exponential Generalized Autoregressive Heteroscedasticity model to examine the dependence structure between Australian equity, bond and money markets from 1988 to 1999. They concluded that the Australian financial futures markets were significantly correlated to movements of volatility interaction and dependence structures of volatility among the three markets showed a strong significance.

Fleischer (2003) examined the linkages between information and volatility on the Australian and US equity, money and bond markets as well as the dependence structure across the two countries by using a generalized method of moment model from 1990 to 2002. The paper found significant strong cross-market and cross-country linkages between the three markets. Wang (2009) proposed an alternative approach for examining volatility linkages between the equity, bond and money markets in the US using implied volatility from the three markets. The author found that correlations between implied volatilities in the equity, bond and money markets are positive, strong and robust. 
Wang (2010) forecasted volatility of the S\&P 500 index market, the Eurodollar futures market, and the 30-year US T-Bond futures market at a daily level using a market-based option-pricing error approach. It compared the 40-day historical volatility, the 60-day historical volatility, the moving average volatility, the EWMA, the ARCH/GARCH volatility and implied volatility. The paper found that implied volatilities outperform the 60-day historical volatility in the equity and money markets and ARCH (1) in the bond market. Ehrmann et al. (2011) estimated the financial transmission between money, bond and equity markets and exchange rates within and between the USA and the euro area with a multifactor model and using the Heteroscedasticity of the asset return to identify the financial transmissions. The paper found that asset prices react strongest to other domestic asset price shocks, but that there are also substantial international spillovers, both within and across asset classes with the dominance of US markets as the main driver of global financial markets.

The econometric and statistical methods used to analyze the linkages between the equity, bond and money markets in literature focus on either the confirmation of the linkages or the effect of information flow to the markets. However, some asymmetric patterns such as booming or crashing during upheaval periods among the markets are possible. With this objective, copula models have been used in recent empirical finance literature. Their use dates back to 1999 in Embrecht et al. (1999), Ane and Kharoubi (2003), Hu (2006), Patton (2006), Choudhury and Bhatti (2006), Turgutlu and Ucer (2007), Li (2010), Nguyen and Bhatti (2012), Aldel and Salma (2012) amongst others.

A copula can be defined as a dependence function between random variables which links the univariate marginals together without loosing any information from the original multivariate distribution. Using a copula model has several advantages in modeling dependence as compared to using the joint distribution directly. First, copula functions are very flexible in modeling dependence since it allows us to separately model marginals and the corresponding dependence structure. Second, copula functions enable us to directly model tail dependence; furthermore, they tell us not only the degree but also the structure of the dependence. Third, copula functions are invariant under transformations of the data while the linear correlation is not. Therefore, its flexibility in model specification allows us to use any specified marginal distributions to join with any available copulas, thus creating complex non-normal distributions which can fully capture dependency. Importantly, some copulas can help model tail dependence or co-movements, which show whether variables boom or crash together.

To date, very little literature explores the analysis of dependence structure between the equity, bond and money markets in Australia, the US and across the two countries. This paper contributes to the existing literature by applying a copula model to study the linkages between the equity, bond and money markets in Australia, the US and across the two countries. These linkages should be taken into consideration since increased knowledge of the interactions among the markets is important in investment decision making process of investors, portfolio managers, derivative dealers, regulatory policy makers, and risk managers. Intuitively, a portfolio manager would consider shifting investment across these markets in order to avoid losses if the linkages across these markets are expected to increase. In other words, if a strong positive linkage exists between two out of the three markets, it means that losses in one market would lead to losses in the other and the portfolio manager may switch a proportion of the portfolio to the rest provided that the new market pair is less correlated. And furthermore, this paper shows an effective and informative way to analyze dependence between variables, especially to provide a better understanding of the co-movements of financial variables as well as the risks associated with dependence structures among them.

With the objective of studying the linkages between the equity, bond and money markets in Australia, the US and across the two countries, we propose the use of the empirical distribution for the distribution of each market and the time-varying copula approach for the joint behavior between the three markets. The advantage of using the empirical distribution is that there is no need to impose any assumptions for the marginal distribution of each market; therefore the estimation is robust and free of any specification errors from the marginal distributions. Additionally, the time-varying copula approach, which was first used by Patton (2006), allows copula parameters to vary over time in terms of evolution equations. It proves to be informative in analyzing the dynamics of dependence structures, providing a better understanding of the fluctuation of dependence measures over time.

The remaining part of this paper is structured as follows. Section 2 describes the methodology used in modeling the dependence structure between the markets, including copula theory, the time-varying copulas and the estimation method is discussed. Section 3 presents the data description, the discussion of empirical results and the main finding of the paper. In the final section, some concluding remarks are made.

\section{Methodology}

Copula theory provides a method of modeling the dependence structure between variables. It helps separate the 
marginal behavior of variables from the dependence structure through the use of distribution functions. The concept of copula was first introduced by Sklar in 1959, but the application of copulas in finance is a relatively new phenomenon, which was initiated by Frees and Valdez (1998) and Embrecht et al. (1999). This section presents brief basic properties of copulas, copula functions with time-varying parameters and the estimation method.

\subsection{Copula in Brief}

A copula can be defined as a function that joins one-dimensional uniformly distributed marginal distribution functions. There are two wide classes of copulas, unconditional and conditional copulas. In this study, we will consider the simple case of bivariate copula.

\section{Unconditional Copula}

Every bivariate distribution F, with margins F1, F2 can be written as:

$$
F\left(x_{1}, x_{2}\right)=C\left[F\left(x_{1}\right) ; F\left(x_{2}\right)\right]
$$

Given a random vector $\mathrm{X}=(\mathrm{x} 1, \mathrm{x} 2)$, the copula of their joint bivariate distribution function can be expressed as:

$$
C(u, v)=F\left(F_{1}^{-1}(u), F_{2}^{-1}(v)\right)
$$

where in the equation (2) the quantile functions of margins are defined as:

$$
F^{-1}(u)=\inf \{x: F(x) \geq u\}, \mathrm{u} \in[0,1]
$$

A bivariate copula is basically a bivariate cumulative distribution function with uniform distributed margins in $[0,1]$. The fundamental theorem for all copula-based analysis - Sklar's theorem - gives out very important results in the continuous case. Let X1 F1 (.) and X2 F2(.) and $\mathrm{H}$ be the joint distribution of (X1, X2). Assume Fl and $\mathrm{F} 2$ are continuous, then there exists a unique copula $\mathrm{C}$ such that:

$$
H\left(x_{l}, x_{2}\right)=C\left(F_{l}\left(x_{l}\right), F_{2}\left(x_{2}\right), \quad \forall(x l, x 2) \in x \Re x \Re\right.
$$

Conversely, if we let $\mathrm{Fl}($.$) and \mathrm{F} 2($.$) be distribution functions and \mathrm{C}$ be a copula, then the function $\mathrm{H}$ is a bivariate distribution function with marginal distributions $\mathrm{Fl}($.$) and \mathrm{F} 2($.$) .$

A bivariate copula is a function $\mathrm{C}$ of two variables with the following properties:

$\mathrm{C}(\mathrm{u}, 0)=\mathrm{C}(0, \mathrm{v})=0, \forall(\mathrm{u}, \mathrm{v}) \in[0,1]$

$\mathrm{C}(\mathrm{u}, 1)=\mathrm{u}, \mathrm{C}(1, \mathrm{v})=\mathrm{v}, \quad \forall(\mathrm{u}, \mathrm{v}) \in[0,1]$;

$\mathrm{Vc}([\mathrm{ul}, \mathrm{u} 2] \mathrm{x}[\mathrm{vl}, \mathrm{v} 2])=\mathrm{C}(\mathrm{u} 2, \mathrm{v} 2)-\mathrm{C}(\mathrm{ul}, \mathrm{v} 2)-\mathrm{C}(\mathrm{u} 2, \mathrm{vl})+\mathrm{C}(\mathrm{ul}, \mathrm{vl}) \geq 0, \quad \forall \mathrm{ul}, \mathrm{u} 2, \mathrm{vl}, \mathrm{v} 2 \in[0,1] ; \mathrm{u} 1 \leq \mathrm{u} 2, \mathrm{vl} \leq$ v2.

Nelsen (1999) showed that every copula is bounded by the so-called Frechet-Hoeffding bounds which are commonly denoted by $\mathrm{W}(\max )$ and $\mathrm{M}(\mathrm{min})$.

$$
\operatorname{Min}(u, v)<C(u, v)<W(u, v)
$$

We can derive copula density by applying Sklar's Theorem and using the relationship between the distribution and the density function. It shows us the important role of copula as dependence functions.

$$
\begin{gathered}
c(u, v)=P(U \leq u, \quad V \leq v)=\int_{0}^{u} \int_{0}^{v} \mathrm{C}(\mathrm{u}, \mathrm{v}) \mathrm{dudv} \\
\mathrm{c}(\mathrm{u}, \mathrm{v})=\frac{\mathrm{f}\left(\mathrm{F}_{1}^{-1}(\mathrm{u}), \mathrm{F}_{2}^{-1}(\mathrm{v})\right)}{\mathrm{f}_{1}\left(\mathrm{~F}_{1}^{-1}(\mathrm{u})\right), \mathrm{f}_{2}\left(\mathrm{~F}_{2}^{-1}(\mathrm{v})\right)} \\
f\left(x_{1} \cdot x_{2}\right)=c\left(F_{1}\left(x_{1}\right), F_{2}\left(x_{2}\right)\right) \cdot f\left(x_{1}\right) \cdot f\left(x_{2}\right)
\end{gathered}
$$

From the density function, we can see that copula splits the distribution into marginal parts and dependence structure (copula) without losing any information. The important point here is that marginal parts (F1(.) and F2(.)) need not to be identical or to belong to the same distribution family.

\section{Conditional Copula}

In financial time series analysis, especially in risk management, random variables conditioned on other variables are of the main interest. Hence, consideration will be given to bivariate conditional copula with the conditioning variable W. Every bivariate distribution F, with margins F1, F2 can be written as:

$$
F\left(x_{1}, x_{2} / w\right)=C\left(F_{1}\left(x_{1} / w\right), F_{2}\left(x_{2} / w\right)\right), \quad \forall x_{1}, x_{2} \in \mathfrak{R} \mathfrak{R}, \mathrm{w} \in \mathrm{W}
$$

Given a random vector $\mathrm{X}=(\mathrm{X} 1, \mathrm{X} 2 / \mathrm{W})$, the copula of their joint distribution function can be expressed as: 


$$
C(u, v / w)=F\left(F_{1}{ }^{l}(u / w), F_{2}{ }^{l}(v / w)\right)
$$

Where the quantile functions of margins is:

$$
F^{l}(u / w)=\inf \{x: F(x / w) \geq u\}, \mathrm{u} \in[0,1], \mathrm{w} \in \mathrm{W}
$$

A bivariate conditional copula is a function $\mathrm{C}$ of two variables with the same properties with unconditional copula.

\subsection{The Time-Varying Copula Model}

In this paper, we will particularly use Gaussian (normal) and Symmetrized Joe-Clayton copulas and their time-varying models in that they are fully describing the general dependence and the left-right tail dependence structure between variables, respectively while the other copulas such as Gumbel copula or Clayton copula can capture only either right tail or left tail dependence. The time-varying copula model is able to capture the time path of dependence structure over time, thus bringing about further understanding of changes in dependence. This section will discuss Gaussian copula, Symmetrized Joe-Clayton copula in details.

\section{Gaussian Copula}

The Gaussian copula is the copula of the multivariate normal distribution. In the bivariate case, the random vector $\mathrm{X}(\mathrm{X} 1, \mathrm{X} 2)$ is bivariate normal if the univariate $\mathrm{F} 1$ and $\mathrm{F} 2$ are Gaussians, and the dependence structure between the margins is described by the copula function.

$$
\begin{gathered}
C(u, v)=\int_{-\infty}^{\Phi-1(u)} \int_{-\infty}^{\Phi-1(u)} \frac{1}{2 \pi \sqrt{1-\delta^{2}}} \exp \left\{-\frac{\mathrm{x}^{2}-2 \delta x y+y^{2}}{2\left(1-\delta^{2}\right)} d x . d y\right. \\
\Phi_{\delta}\left(\Phi^{-1}(u), \Phi^{-1}(v)\right),-1 \leq \delta \leq 1
\end{gathered}
$$

In which $\Phi$ and $\Phi_{\delta}$ the univariate and bivariate standard normal cdfs, respectively, and $\delta$ is the correlation coefficient between random variables.

In order to allow for time variation in the copula, we will allow the dependence parameter to be time varying by following some evolution processes while the copula's functional form is fixed. Following Patton (2006), we propose the following evolution dynamics for $\delta_{\mathrm{t}}$ :

$$
\delta t=\hat{\Lambda}\left(\omega \delta+\beta \delta \cdot \delta t-1+a \delta \cdot \frac{1}{10} \sum_{j=1}^{10}\left[\Phi^{-1}\left(\mathrm{u}_{\mathrm{t}-\mathrm{j}}\right) \cdot \Phi^{-1}\left(\mathrm{v}_{\mathrm{t}-\mathrm{j}}\right)\right]\right)
$$

where $\hat{\Lambda}(\mathrm{x})=\frac{1-\mathrm{e}^{-\mathrm{x}}}{1+\mathrm{e}^{-\mathrm{x}}}$ is the modified logistic transformation, aiming to keep $\delta \mathrm{t}$ within the interval $(-1,1)$ at all times. The above equation assumes that the copula dependence parameter follows an ARMA $(1,10)$ type process, in which the $\left(\beta_{\delta} \delta_{t-1}\right)$ captures the persistence effect and the mean of the product of the last ten observations of the transformed variables $\Phi-1(\mathrm{ut}-\mathrm{j})$ and $\Phi-1(\mathrm{vt}-\mathrm{j})$ captures the variation effect in dependence.

\section{Symmetrized Joe-Clayton Copula (SJC)}

Basically, the Symmetrized Joe-Clayton copula is a modification of the 1997 Joe-Clayton copula and proposed by Patton (2006). The 1997 Joe-Clayton copula is a Laplace transformation of Clayton's copula and its function is defined as follows:

$$
C j c(u, v \mid T U, T L)=1-([1-(1-u) k]-\gamma+[1-(v) k]-\gamma-1-1 / \gamma) 1 / k
$$

where

$$
\begin{gathered}
k=1 / \log 2\left(2-T^{U}\right) \\
\gamma=-1 / \log 2\left(T^{L}\right)
\end{gathered}
$$

and

$$
T U \in(0,1), T L \in(0,1) .
$$

Unlike the Gaussian copula, the Joe-Clayton copula exposes tail dependence which captures the behavior of variables during extreme events. In this function, TU and TL are upper tail and lower tail dependence, respectively. The upper tail dependence is defined as:

$$
\mathrm{T}^{\mathrm{U}}=\lim _{\varepsilon \rightarrow 1} \operatorname{Pr}[\mathrm{U}>\varepsilon \mid \mathrm{V}>\varepsilon]=\lim _{\varepsilon \rightarrow 1} \operatorname{Pr}[\mathrm{U}>\varepsilon \mid \mathrm{V}>\varepsilon]=\lim _{\varepsilon \rightarrow 1}(1-2 \varepsilon+\mathrm{C}(\varepsilon, \varepsilon)) /(1-\varepsilon)
$$

If this limit exists, the copula shows upper tail dependence when $\mathrm{TU} \in(0,1]$ and no tail dependence when $\mathrm{TU}=0$. 
Similarly, the lower tail dependence is defined as:

$$
\mathrm{T}^{\mathrm{L}}=\lim _{\varepsilon \rightarrow 0} \operatorname{Pr}[\mathrm{U} \leq \varepsilon \mid \mathrm{V} \leq \varepsilon]=\lim _{\varepsilon \rightarrow 0} \operatorname{Pr}[\mathrm{U} \leq \varepsilon \mid \mathrm{V} \leq \varepsilon]=\lim _{\varepsilon \rightarrow 0} \mathrm{C}(\varepsilon, \varepsilon) / \varepsilon
$$

If this limit exists, the copula shows lower tail dependence when $\mathrm{TL} \in(0,1]$ and no tail dependence when $\mathrm{TL}=0$. By the functional form, the Joe-Clayton copula will always show asymmetric tail dependence even in case that the two tail dependence measures are totally identical. In order to avoid this problem, we will use Symmetrized Joe-Clayton copula, whose functional form is defined as:

$$
\operatorname{Csjc}\left(u, v \mid T^{U}, T^{L}\right)=0.5 \cdot\left[\operatorname{Cjc}\left(u, v \mid T^{U}, T^{L}\right)+\operatorname{Cjc}\left(1-u, 1-v \mid T^{U}, T^{L}\right)+u+v-1\right]
$$

where CJC is Joe-Clayton copula.

The Symmetrized Joe-Clayton copula is more attractive than the original Joe-Clayton because it can be symmetric when $\mathrm{T}^{\mathrm{U}}=\mathrm{T}^{\mathrm{L}}$. And also, it has the advantage of capturing the upper and lower tail dependence of joint distribution at the same time, especially when examining the behavior of financial variables in extreme situations like market boom or crash periods. Therefore, the symmetrized Joe-Clayton copula is a good copula to analyze dependence linkages between financial variables.

Similar to the dynamics $\delta t$ in the above Gaussian copula, we also allow for time variation in the Symmetrized Joe-Clayton copula. We propose the following process for the copula's parameters as follows (also see Patton, 2006):

$$
\begin{aligned}
& \mathrm{T} \frac{\mathrm{u}}{\mathrm{t}}=\Lambda\left(\omega_{\mathrm{u}}+\beta_{\mathrm{u}} \mathrm{T}_{\mathrm{t}-1}^{\mathrm{u}}+\alpha^{\mathrm{U}} \frac{1}{10} \sum_{\mathrm{j}=1}^{10}\left|\mathrm{u}_{\mathrm{t}-\mathrm{j}}-\mathrm{v}_{\mathrm{t}-\mathrm{j}}\right|\right) \\
& \mathrm{T} \frac{\mathrm{L}}{\mathrm{t}}=\Lambda\left(\omega_{\mathrm{L}}+\beta_{\mathrm{L}} \cdot \mathrm{T}_{\mathrm{t}-1}^{\mathrm{L}}+\alpha^{\mathrm{L}} \cdot \frac{1}{10} \sum_{\mathrm{j}=1}^{10}\left|\mathrm{u}_{\mathrm{t}-\mathrm{j}}-\mathrm{v}_{\mathrm{t}-\mathrm{j}}\right|\right)
\end{aligned}
$$

where $\Lambda \equiv \frac{1}{1+\mathrm{e}^{-\mathrm{x}}}$ is the logistic transformation, used to keep $\mathrm{T}^{\mathrm{U}}$ and $\mathrm{T}^{\mathrm{L}}$ within the interval of $(0,1)$ at all times. The dynamics of $\mathrm{T}^{\mathrm{U}}$ and $\mathrm{T}^{\mathrm{L}}$ follows $\operatorname{ARMA}(1,10)$ type process in which the autoregressive term, $\left(\beta . \mathrm{T}_{\mathrm{t}-1}\right)$ and a forcing variable, $\alpha \frac{1}{10} \sum_{j=1}^{10}\left|\mathrm{u}_{\mathrm{t}-\mathrm{j}}-\mathrm{v}_{\mathrm{t}-\mathrm{j}}\right|$, represent persistent effect and variation in dependence, respectively. The lag of 10 is used to make it comparable with the dynamics in the above Gaussian copula.

\subsection{The Estimation Methods}

In general, there are two estimation methods available for copula models. One method is to estimate marginal distributions and the copula function at the same time. If the maximum likelihood estimation is used, the likelihood function is computed based on the following density:

$$
f\left(x_{1}, x_{2}\right)=c\left(F_{1}\left(x_{1}\right), F_{2}\left(x_{2}\right)\right) \cdot f\left(x_{1}\right) \cdot f\left(x_{2}\right)
$$

However, conducting this method may be difficult due to the complexity of the model and estimation of many parameters at the same time. Also, the marginal distributions need to be specified and specification errors, if any, will affect the estimation of the copula. Alternatively, the second method, inference for the margins (IMF) proposed by Joe and Xu (1996), is usually used to estimate copula parameters. It separates the estimation into two steps. In the first step, the marginal distributions are estimated. In the second step, we plug the estimated marginal distributions into the copula, and use maximum likelihood estimation method to estimate the parameters in the copula. By doing this, the density estimation of each margin does not affect the estimation of the copula parameter because each margin has been estimated in the first step and is constant in the second step.

This paper estimates the copula model using the two-step IMF method with the empirical distribution for marginals. That is, we estimate the marginal distribution non-parametrically and then plug the empirical cumulative density functions (CDFs) into the copula. Using the empirical CDF will bring about robust and specification-error-free estimates since we do not impose any parametric assumptions for the marginals. The empirical CDF is generated as follows.

Assume a sample of $\left(\mathrm{X}_{1}, \mathrm{X}_{2}, \mathrm{X}_{3}, \ldots, \mathrm{X}_{\mathrm{n}}\right)$ is generated independently from a univariate distribution $\mathrm{F}_{\mathrm{X}}(\mathrm{x})$, the empirical $\mathrm{CDF}$ of $\mathrm{X}$ can be estimated as follows:

$$
\hat{\mathrm{F}}_{\mathrm{x}}(\mathrm{x})=\frac{1}{\mathrm{n}+1} \sum_{\mathrm{t}=1}^{\mathrm{n}} 1\left(\mathrm{x}_{\mathrm{t}} \leq \mathrm{x}\right)
$$

Let $\mathrm{u}=\hat{\mathrm{F}}_{\mathrm{X}}(\mathrm{x})$ and $\mathrm{v}=\hat{\mathrm{F}}_{\mathrm{Y}}(\mathrm{y})$ denote the empirical CDFs of two random variables, $\mathrm{X}$ and $\mathrm{Y}$, the joint 
distribution can be written as:

$$
C(u, v ; \delta)=C\left(\hat{\mathrm{F}}_{X}(x), \quad \hat{\mathrm{F}}_{Y}(y) ; \delta\right)
$$

The copula density is:

$$
\mathrm{c}(\mathrm{u}, \mathrm{v} ; \delta)=\frac{\delta^{2} \mathrm{C}(\mathrm{u}, \mathrm{v} ; \delta)}{\partial \mathrm{u} . \partial \mathrm{v}}
$$

Then, the joint density of $\mathrm{Z}(\mathrm{X}, \mathrm{Y})$ is:

$$
\begin{aligned}
\mathrm{c}(\mathrm{u}, \mathrm{y} ; \delta) & =\frac{\delta^{2} \mathrm{C}(\mathrm{u}, \mathrm{v} ; \delta)}{\partial \mathrm{u} \cdot \partial \mathrm{v}} \cdot \frac{\delta \mathrm{u}}{\delta \mathrm{x}} \frac{\delta \mathrm{v}}{\delta \mathrm{y}} \\
& =\mathrm{c}(\mathrm{u}, \mathrm{v} ; \delta) \cdot \widehat{\mathrm{f}}_{\mathrm{x}}(\mathrm{x}) \cdot \widehat{\mathrm{f}}_{\mathrm{y}}(\mathrm{y})
\end{aligned}
$$

Hence, the log-likelihood function will be:

$$
\begin{aligned}
L(x, y ; \delta) & =\ln \left[c(u, v ; \delta), \widehat{\mathrm{f}}_{x}(x), \hat{\mathrm{f}}_{Y(y)]}\right. \\
& =\ln \left[c\left(\hat{\mathrm{F}}_{x}(x), \hat{\mathrm{F}}_{y(}(y) ; \delta\right) . \widehat{\mathrm{f}}_{x}(x), \widehat{\mathrm{f}}_{Y}(y)\right] \\
& =L_{C}+L_{x}+L_{Y}
\end{aligned}
$$

where $\mathrm{L}_{\mathrm{C}}=\ln (\mathrm{C}(\mathrm{u}, \mathrm{v} ; \delta)), \mathrm{L}_{\mathrm{X}}=\ln \hat{\mathrm{F}}_{\mathrm{X}}(\mathrm{x}), \mathrm{L}_{\mathrm{Y}}=\ln \hat{\mathrm{F}}_{\mathrm{Y}}(\mathrm{y})$.

Then, copula parameter is estimated given the result from the empirical CDFs, $\hat{\mathrm{F}}_{\mathrm{X}}(\mathrm{x})$ and $\hat{\mathrm{F}}_{\mathrm{Y}}(\mathrm{y})$ as follows:

$$
\tilde{\delta}=\arg \max _{c}\left(x, y ; \delta, \hat{\mathrm{F}}_{x}(x), \hat{\mathrm{F}}_{Y}(y)\right)
$$

This method will produce normal and asymptotically efficient parameter estimates as noted in Joe and $\mathrm{Xu}$ (1999), Joe (1997) and Patton (2006). We also applied a filtering GARCH process to each return series as proposed in Engle (2002) to overcome the problem of conditional heteroscedasticity in financial data. Then, the filtered series will be used in the estimation process. This GARCH filter proved to be suitable for return series in the estimation process as in $\mathrm{Hu}(2006)$ and Turgutlu and Ucer (2007).

In the literature, different kinds of tests have been used in order to test copula specification, including Fermanian (2005), Chen and Fan (2005), Genest et al. (2006) and Hans (2007). The most widely used criterion of fit test which allows to evaluate the copulas according to the fit is the so called Akaike Information Criterion (AIC). AIC is defined as followed.

$$
A I C=-2\{\log (\text { likelihood })+k\}
$$

where $\mathrm{k}$ is the number of parameters in the model. The lower the AIC is the better is the model. Therefore, the model with the lowest AIC should be considered as the best fit one.

Additionally, Bayesian Information Criterion (BIC) is also used to select the best fitted model with the following value:

$$
B I C=-2 \log (\text { likelihood })+k \cdot \log (n)
$$

where is the number of observations and is the number of parameters in the model. The model with the lowest BIC should be considered as the best fit.

\section{Empirical Results}

\subsection{Data}

The paper uses daily data collected for the period from June 1992 to November 2008 from DataStream International. As proxies for the equity, bond and money markets in Australia, we use All Ordinaries Share Price Index futures contract, the Government bond futures contract and the 90-day bank bill futures contract traded on the Sydney Futures Exchange. The problem with non-synchronous trading inherent in return indices is avoided since the futures markets are considered and the selected futures contracts are actively traded. As proxies for the equity, bond and money markets in the US, we use the S\&P 500 futures contract traded on the Chicago Mercantile Exchange (CME), the 30-year Treasury bond futures contract traded on the Chicago Board of Trade, and the 3-month Eurodollar futures contract traded on CME. These contracts have a quarterly expiration cycle.

We computed the daily percentage returns for each index by taking logarithm of the current price and the previous day's price. In order to generate continuous return series, we chose the nearest-maturity contract. For 
the Australian equity and bond futures contracts, the switchover only occurs on the last day of trading of the old futures contract, whereas for the Australian money market, it was 30 days out from the last trading day of the expiring contract.

Table 1. Statistics for the Australian markets

\begin{tabular}{llll} 
& Equity market & Bond market & Money market \\
\cline { 2 - 3 } Panel A: Descriptive statistics & & & \\
Min & -0.08492 & -0.005494 & -0.01682 \\
Median & 0 & 0 & 0 \\
Max & 0.1021 & 0.004334 & 0.009645 \\
Mean & 0.0001858 & 0.00001148 & $4.588 \mathrm{e}-006$ \\
Standard deviation & 0.01046 & 0.000813 & 0.0007204 \\
Skewness & -0.0898 & -0.389 & -3.822 \\
Kurtosis & 11.71 & 6.462 & 104.5 \\
JB Sta (p-vl) & $13607.63(0.00)$ & $2258.385(0.00)$ & $1858379(0.00)$ \\
No Obs & 4304 & 4304 & 4304 \\
Panel B: Linear correlation & & & \\
Equity market & 1 & 1 & \\
Bond market & 0.084273 & 0.505988 & 1 \\
Money market & 0.037208 & & \\
\hline
\end{tabular}

Notes: p-value in parenthesis.

Table 2. Statistics for the United States markets

\begin{tabular}{llll}
\hline & Equity market & Bond market & Money market \\
\hline Panel A: Descriptive statistics & & & \\
Min & -0.104 & -0.03047 & -0.008677 \\
Median & 0.000216 & 0 & 0 \\
Max & 0.132 & 0.02976 & 0.00528 \\
Mean & 0.0001771 & 0.0001034 & $5.391 \mathrm{e}-006$ \\
Standard deviation & 0.01174 & 0.005788 & 0.0005269 \\
Skewness & 0.0231 & -0.3278 & -1.655 \\
Kurtosis & 15.66 & 4.716 & 49.3 \\
JB Sta (p-vl) & $28747.56(0.00)$ & $605.2168(0.00)$ & $386375.3(0.00)$ \\
No Obs & 4304 & 4304 & 4304 \\
Panel B: Linear correlation & & & \\
Equity market & 1 & & \\
Bond market & -0.08256 & 1 & 1 \\
Money market & -0.0037 & 0.368678 & \\
Panel C: Linear correlation (with Australian markets in USD) & 0.024034 \\
Equity market & 0.070139 & -0.02369 & 0.034335 \\
Bond market & 0.019757 & -0.01329 & 0.051792 \\
Money market & 0.020194 & -0.01962 & \\
\hline
\end{tabular}

Notes: p-value in parenthesis. USD: the US dollar.

Panel A of Tables 1 and 2 provides descriptive statistics of daily returns of the equity, bond and money markets in Australia and the US. It shows that all sample means vary from $4.6 * 10^{-6}$ to $1.86 * 10^{-4}$. The smallest return is from the Australian money market and the highest return is from the Australian equity market. In the US markets, the highest mean return is that of the equity market and the lowest mean return is that of the money market. This is in line with expectation that the highest returns are for the equity futures contracts as the underlying assets appear to be riskier than long-term government bonds. All means are relatively small in comparison with their standard deviation, indicating remarkably high volatility in all series. The skewnesses of most series are different from zero with skewing to the left, except the US equity market series which are skewed to the right. Generally, if the values of kurtosis are higher than 3.0, then the return series are more 
peaked and have fatter tails than normal distribution. Intuitively, all se-ries show excess kurtosis, ranging from 4.7 to 104.5, in which the Australian money market series displays the highest kurtosis. Also, the Jarque-Bera test with p-value of 0.00 strongly rejects the null hypothesis of normality in all return series.

Panel B of Table 1 shows linear correlations among the Australian equity, bond and money markets. The result shows that the correlation between the equity market and bond market is approximately $8.43 \%$, that of the equity market and the money market is $3.7 \%$ and that of the bond market and the money market is $51 \%$. Panel B of Table 2 shows the linear correlations among the US futures markets. The correlation between the equity market and bond market is $-8.3 \%$ and the equity and money market is $-0.37 \%$ and that of the bond market and money market is $36.87 \%$. As can be seen, in Australia, the bond and money market are most strongly correlated using the returns and the equity and money market are the least strongly correlated. In the US, the correlation of the bond and money market is also the strongest, however, the weakest correlation is that of the equity and bond market. Panel C of Table 2 shows the cross-market correlations of returns. The strongest correlation is that of the US and Australian equity market of 7\%, followed by the correlation of the US-Australian money market of 5.2\%. The US bond market and the Australian equity market are the least correlated with correlation of $-2.4 \%$. The US bond market has negative correlation with the Australian equity, bond and money markets.

Table 3. Estimated parameters of Australian pairs

\begin{tabular}{|c|c|c|c|}
\hline & AusEquity-AusBond & AusEquity-AusMoney & AusBond-AusMoney \\
\hline \multicolumn{4}{|c|}{ Panel A1: Gaussian copula } \\
\hline$\delta$ & $0.0816^{*}$ & $0.0653 *$ & $0.6569 * *$ \\
\hline Log likelihood & -14.3898 & -9.2046 & $-1.2155 \mathrm{e}+003$ \\
\hline AIC & -28.7791 & -18.4086 & $-2.4311 \mathrm{e}+003$ \\
\hline BIC & -28.7776 & -18.4072 & $-2.4311 \mathrm{e}+003$ \\
\hline \multicolumn{4}{|c|}{ Panel A2: Time varying Gaussian copula } \\
\hline$\omega$ & $0.0024 *$ & $-0.0003 *$ & $-0.4526^{* *}$ \\
\hline$\alpha$ & $0.1068^{* *}$ & $0.0364 * *$ & $0.0473 * *$ \\
\hline$\beta$ & $1.9427^{*}$ & $1.9865^{*}$ & $3.0501 * * *$ \\
\hline Log likelihood & -165.7348 & -68.4142 & $-1.2286 \mathrm{e}+003$ \\
\hline AIC & -331.4682 & -136.8271 & $-2.4572 \mathrm{e}+003$ \\
\hline $\mathrm{BIC}$ & -331.4637 & -136.8226 & $-2.4572 \mathrm{e}+003$ \\
\hline \multicolumn{4}{|c|}{ Panel B1: Symmetrised Joe-Clayton copula } \\
\hline$\tau^{\mathrm{U}}$ & $0.0001 * * *$ & $0.0038^{*}$ & $0.4462 *$ \\
\hline$\tau^{\mathrm{L}}$ & $0.0293^{*}$ & $0.0008^{* *}$ & $0.4700 *$ \\
\hline Log likelihood & -31.8142 & -17.1798 & $-1.1984 \mathrm{e}+003$ \\
\hline AIC & -63.6274 & -34.3587 & $-2.3967 \mathrm{e}+003$ \\
\hline $\mathrm{BIC}$ & -63.6244 & -34.3557 & $-2.3967 \mathrm{e}+003$ \\
\hline \multicolumn{4}{|c|}{ Panel B2: Time varying symmetrised Joe-Clayton copula } \\
\hline$\omega^{\mathrm{U}}$ (upper tail) & $-9.3414^{*}$ & $3.3472 * *$ & $-1.9624 *$ \\
\hline$\alpha^{\mathrm{U}}$ & $-5.1151 * *$ & $-25.0000^{*}$ & $-0.2708^{* *}$ \\
\hline$\beta^{\mathrm{U}}$ & $0.0043^{*}$ & $-8.9010^{*}$ & $4.0087 * *$ \\
\hline$\omega^{\mathrm{L}}$ (lower tail) & $3.6194 *$ & $-8.7045 * *$ & $1.9591 *$ \\
\hline$\alpha^{\mathrm{L}}$ & $-22.2959 * *$ & $-12.0602 *$ & $-6.2325^{* *}$ \\
\hline$\beta^{\mathrm{L}}$ & $-4.3664 *$ & $-0.0028 * *$ & $-2.2150^{* *}$ \\
\hline Log likelihood & -63.1554 & -27.4730 & $-1.2344 \mathrm{e}+003$ \\
\hline AIC & -126.3081 & -54.9433 & $-2.4687 \mathrm{e}+003$ \\
\hline $\mathrm{BIC}$ & -126.2992 & -54.9344 & $-2.4687 \mathrm{e}+003$ \\
\hline
\end{tabular}

Notes: AusEquity, AusBond, and AusMoney are Australian equity, bond, and money market, respectively. *, **, *** denote significance at $10 \%, 5 \%, 1 \%$, respectively.

\subsection{Estimated Results}

\subsubsection{The Australian Markets}

The estimated results for the Australian equity, bond and money markets are reported in Table 3. Firstly, in the constant dependence case, Panel A1 in Table 3 reports the estimated parameters between the three markets. The 
estimated Gaussian copula correlations between the three markets are different from their linear correlations in Table 1. Specifically, the correlation between the equity market and bond market is approximately 0.08 , decreased by $3.2 \%$ as compared to its linear correlation. The correlations of equity-money market and bond-money market increased by $75 \%$ and $30 \%$, respectively as compared to their linear correlations.

Panel B1 in Table 3 reports the estimated parameters of Symmetrized Joe-Clayton copula. It shows that equity market and bond market exhibit left-tail dependence since the left tail's measure is 0.029 and that of the right-tail is 0.00 . This implies that the equity market and bond market in Australia are likely to go down together rather than go up at the same time. In contrast, the equity-money market pair shows right-tail dependence with upper-tail measure of 0.0038 , which is slightly higher than that of the left tail of 0.0008 . This indicates these two markets are likely to go up together. The relationship between the bond market and money market in Australia exhibits both right-tail and left-tail dependence, implying that these two markets are likely to boom and crash together. However, there is a higher possibility that these two markets crash at the same time since the left-tail measure is slightly higher than the right-tail one.

Secondly, the results of time-varying copulas are reported in Panel A2 and B2 in Table 3. The dynamics of dependence measures between markets are captured by the coefficients, $\alpha$ and $\beta$ in the evolution equation. The time path of dependence measures between markets is shown in Figure 1.
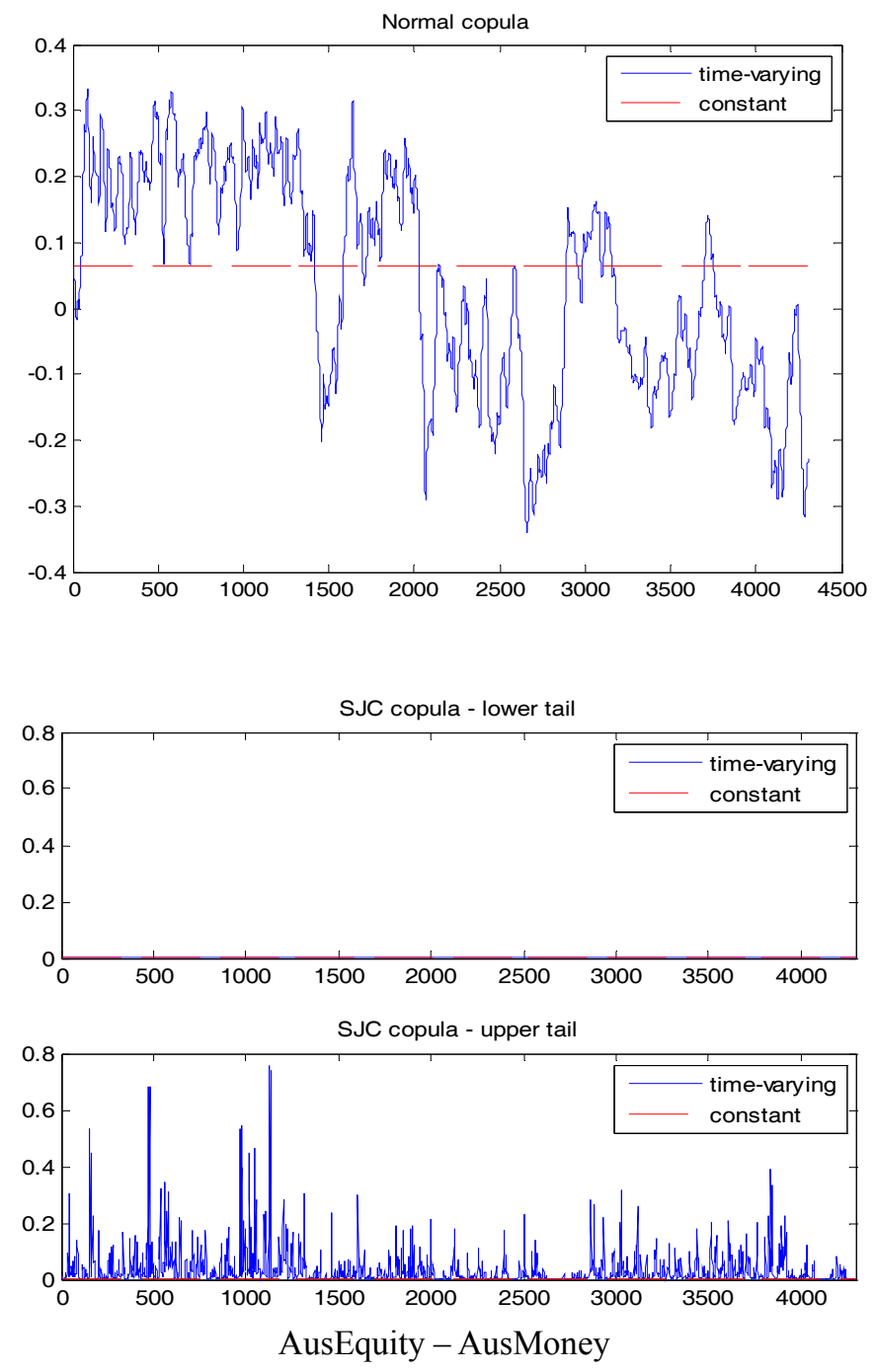

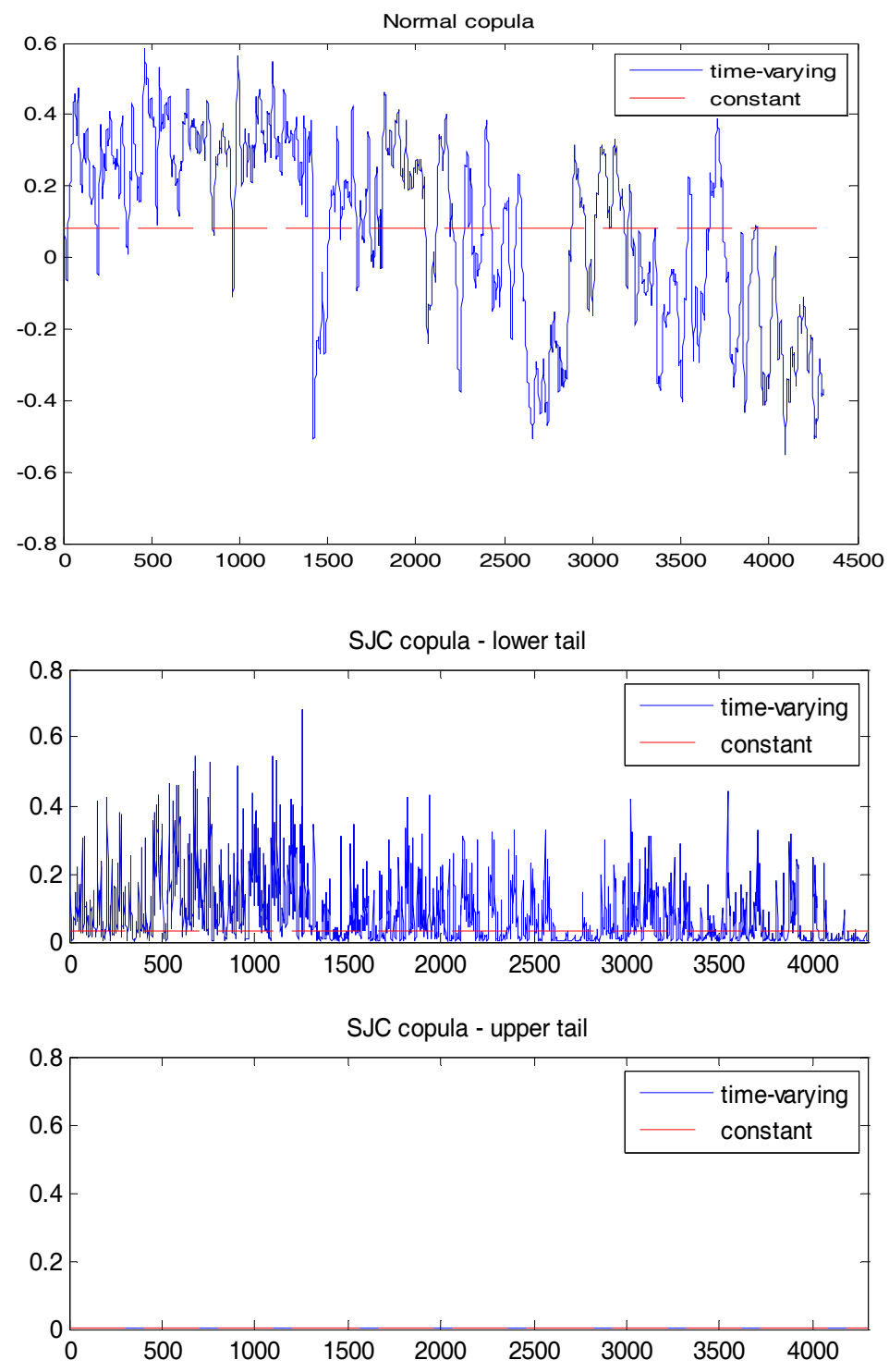

AusEquity - AusBond

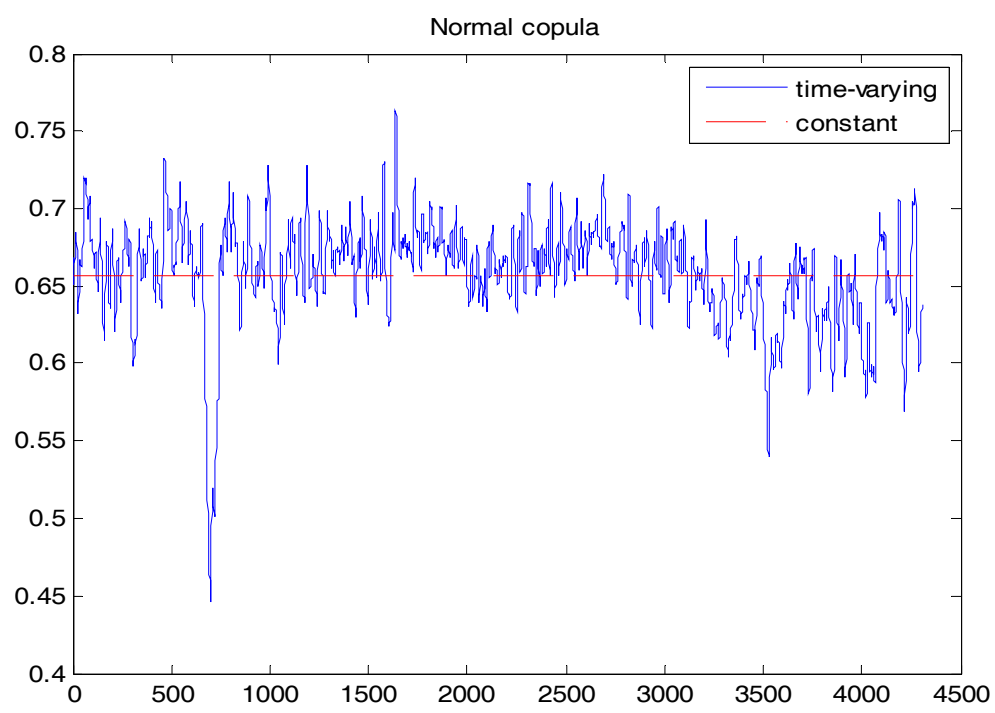



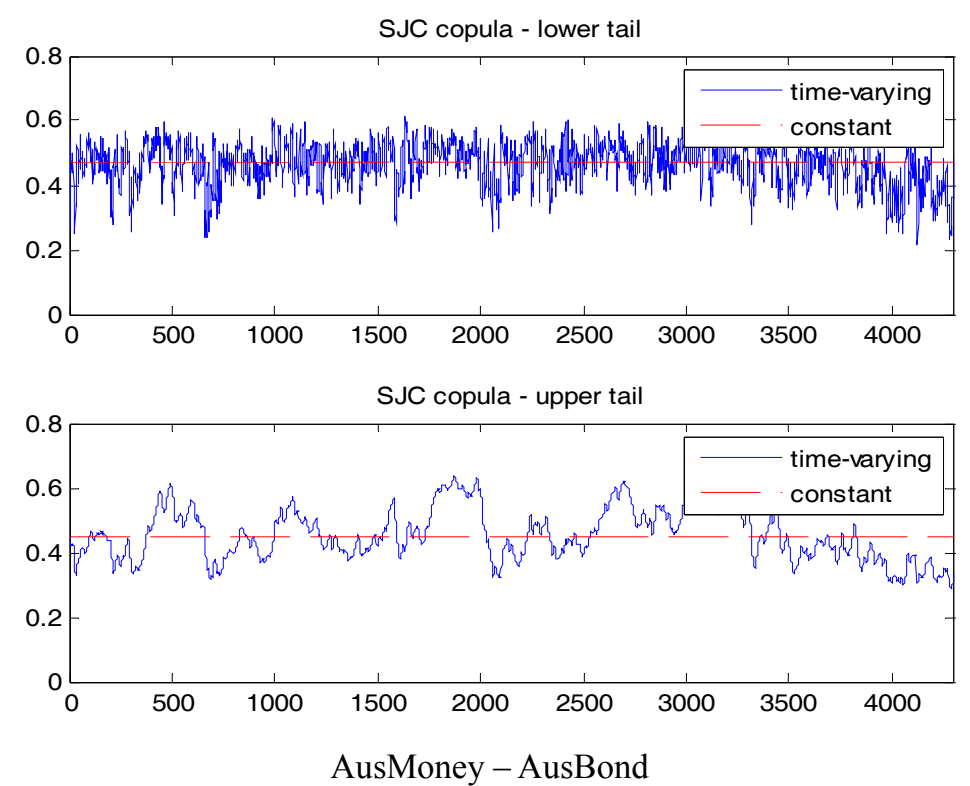

Figure 1. Time-varying copulas for the Australian markets

Notes: In the horizontal time line, it starts from 1992 with intervals of 2 years. Therefore, 500 means 1994; 1000 means 1996, 1500 means 1998, 2000 means 2000, 2500 means 2002, 3000 means 2004, 3500 means 2006, and 4000 means 2008.

The time path of time-varying Normal copula for the equity-money and equity-bond market pairs seem to be informative for analysis, while their SJC copula's time paths are close to white-noise, which is uninformative. The time path of time-varying Normal copula for equity-money market fluctuates around its constant dependence measure, ranging from -0.35 to 0.35 . From 1992 to 1998 , these two markets are positively correlated, however, its correlation is really volatile after 1998. The highest point is 0.3 in the middle of 1998 and the lowest point is -0.35 around mid 2002. After 2007, these two markets are negatively correlated. The time path of time-varying Normal copula for equity-bond market swings around its constant dependence measure, ranging from -0.5 to 0.6 . Before 1998 , these two markets' correlation mainly is above zero, then decreased sharply to -0.5 early 1998; after that, it is really volatile. During 2008 , the correlation is under zero, ranging from -0.5 to -0.2 , implying that these two markets have moved in opposite directions with relatively strong negative correlation.

The time path of time-varying Normal copula and SJC copula's lower tail of money and bond markets in Australia seem to be uninformative since they look like white noise. However, their time path of SJC's upper tail seems to be informative in analyzing the ups and downs of upper tail dependence. It ranges from 0.3 to 0.65 , peaking at 0.65 three times in early 1994, 2000, and 2003. During 2008, it fluctuated within the interval of 0.3 to 0.4 , implying that these two markets recently have considerably positive correlation. Furthermore, we use AIC criteria in order to choose the best copula among four copulas. The time-varying Gaussian copula is the best model for the dependence of the equity-bond market and the equity-money market in Australia. This implies that these markets have a tendency to boom and crash together in a symmetric fashion. The time-varying SJC copula is the best model for the dependence between bond market and money market in Australia, indicating that these two markets show both left tail and right tail dependence.

\subsubsection{The US Markets}

Table 4 summarizes estimated parameters of copulas for the US markets. First, Panel A1 reports the parameters of Gaussian copula. The dependence parameters of equity-bond and equity-money pairs in the US changed their sign from negative to positive one. The parameter of equity-bond pair is from -0.08 to 0.04 , and that of equity-money pair is from -0.037 to 0.001 . This might be due to the biasedness of linear correlation. The dependence parameter of bond-money pair increased by $47 \%$ from 0.37 to 0.54 , indicating very strong correlation between these two markets in the US. 
Table 4. Estimated parameters of the US pairs

\begin{tabular}{|c|c|c|c|}
\hline & USEquity-USBond & USEquity-USMoney & USBond-USMoney \\
\hline \multicolumn{4}{|c|}{ Panel A1: Gaussian copula } \\
\hline$\delta$ & $0.0401^{* *}$ & $0.0011 *$ & $0.5425 * *$ \\
\hline Log likelihood & -3.4585 & -0.0024 & -750.0177 \\
\hline AIC & -6.9165 & -0.0044 & $-1.5000 \mathrm{e}+003$ \\
\hline $\mathrm{BIC}$ & -6.9150 & -0.0029 & $-1.5000 \mathrm{e}+003$ \\
\hline \multicolumn{4}{|c|}{ Panel A2: Time varying Gaussian copula } \\
\hline$\omega$ & $0.0026^{* *}$ & $-0.0004 *$ & $1.8260 *$ \\
\hline$\alpha$ & $0.1219^{*}$ & $0.0274 * *$ & $-0.1677 * *$ \\
\hline$\beta$ & $1.9619^{*}$ & $2.0042 * * *$ & $-0.9464^{* *}$ \\
\hline Log likelihood & -242.6603 & -91.8669 & -752.1746 \\
\hline AIC & -485.3202 & -183.7333 & $-1.5043 \mathrm{e}+003$ \\
\hline $\mathrm{BIC}$ & -485.3187 & -183.7318 & $-1.5043 \mathrm{e}+003$ \\
\hline \multicolumn{4}{|c|}{ Panel B1: Symmetrised Joe-Clayton copula } \\
\hline$\tau^{\mathrm{U}}$ & $0.0095^{*}$ & $0.0053 * *$ & $0.3612 *$ \\
\hline$\tau^{\mathrm{L}}$ & 0.0000 & 0.0000 & $0.3621 * *$ \\
\hline Log likelihood & -12.5013 & -7.2847 & -791.0618 \\
\hline AIC & -25.0022 & -14.5690 & $-1.5821 \mathrm{e}+003$ \\
\hline $\mathrm{BIC}$ & -25.0007 & -14.5675 & $-1.5821 \mathrm{e}+003$ \\
\hline \multicolumn{4}{|c|}{ Panel B2: Time varying Symmetrised Joe-Clayton copula } \\
\hline$\omega^{\mathrm{U}}$ (upper tail) & $3.4847 * *$ & $2.6484 *$ & $-1.8066^{* *}$ \\
\hline$\alpha^{\mathrm{U}}$ & $-22.9059 * *$ & $-21.3873 *$ & $-0.7969 * * *$ \\
\hline$\beta^{\mathrm{U}}$ & $-1.7247 * *$ & $-1.9324 * *$ & $3.8598^{*}$ \\
\hline$\omega^{\mathrm{L}}$ (lower tail) & $-20.7964 * *$ & $-24.9998^{*}$ & $1.7287^{*}$ \\
\hline$\alpha^{\mathrm{L}}$ & $-0.0001 * * *$ & -0.0000 & $-6.1240 * *$ \\
\hline$\beta^{\mathrm{L}}$ & -0.0000 & 0 & $-3.0903^{*}$ \\
\hline Log likelihood & -66.6731 & -15.4648 & -822.5908 \\
\hline $\mathrm{AIC}$ & -133.3458 & -30.9291 & $-1.6452 \mathrm{e}+003$ \\
\hline $\mathrm{BIC}$ & -133.3443 & -30.9276 & $-1.6452 \mathrm{e}+003$ \\
\hline
\end{tabular}

Notes: USEquity, USBond, and USMoney are the US equity, bond, and money market, respectively, ${ }^{*}, * * * *$ denote significance at $10 \%$, $5 \%, 1 \%$, respectively.

Panel B1 in Table 4 shows that equity-bond and equity-money pairs exhibit upper tail dependence with the upper tail dependence measures of 0.0095 and 0.0053 , respectively. This implies the equity market and the bond market in the US are likely to go up together. It is also the case for the US equity and money markets. However, there is a higher possibility that the US equity and bond markets will boom at the same time as compared to the US equity and money markets since its upper tail dependence measure is stronger than that of the US equity and money markets. Interestingly, the US bond and money markets show both upper and lower tail dependence with relatively equal measures. This indicates that these two markets are likely to boom and crash symmetrically.

Second, in the time-varying case, Panels A2 and B2 in Table 4 report all parameters of time-varying Gaussian copula and SJC copula and their time paths are shown in Figure 2. 

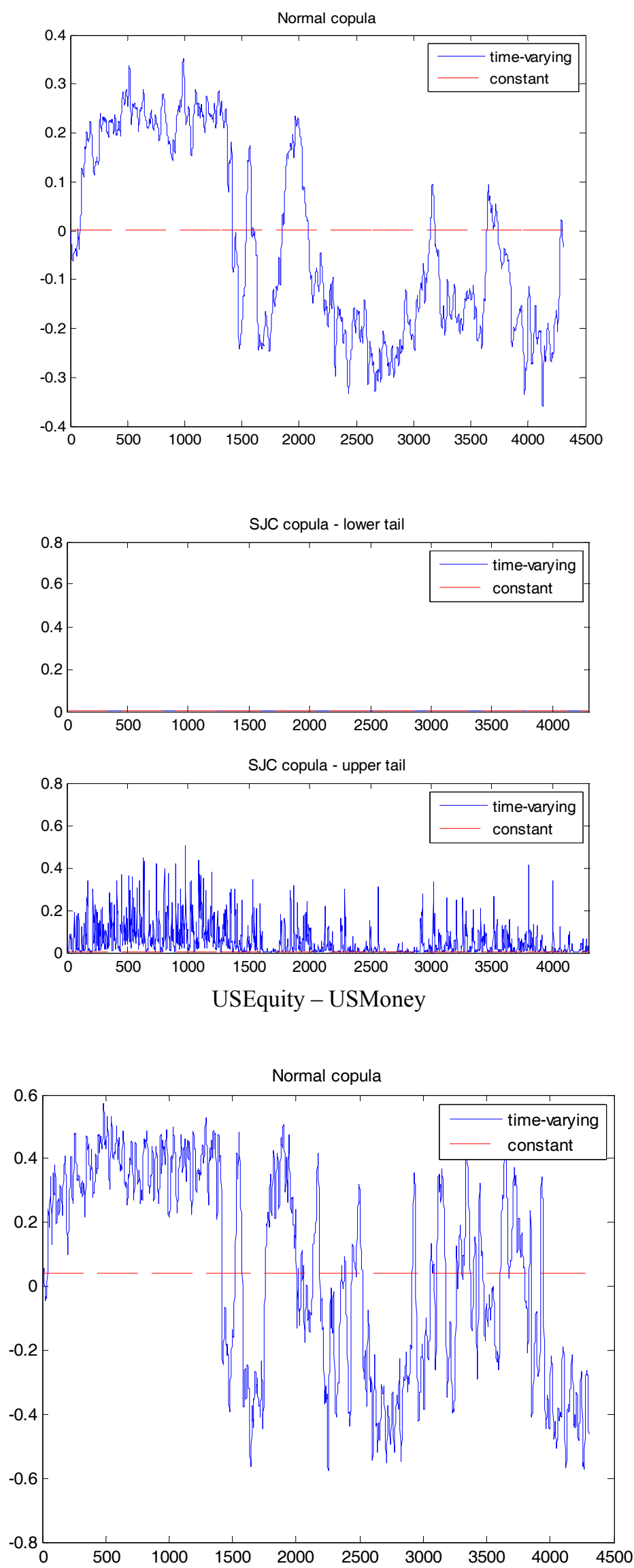

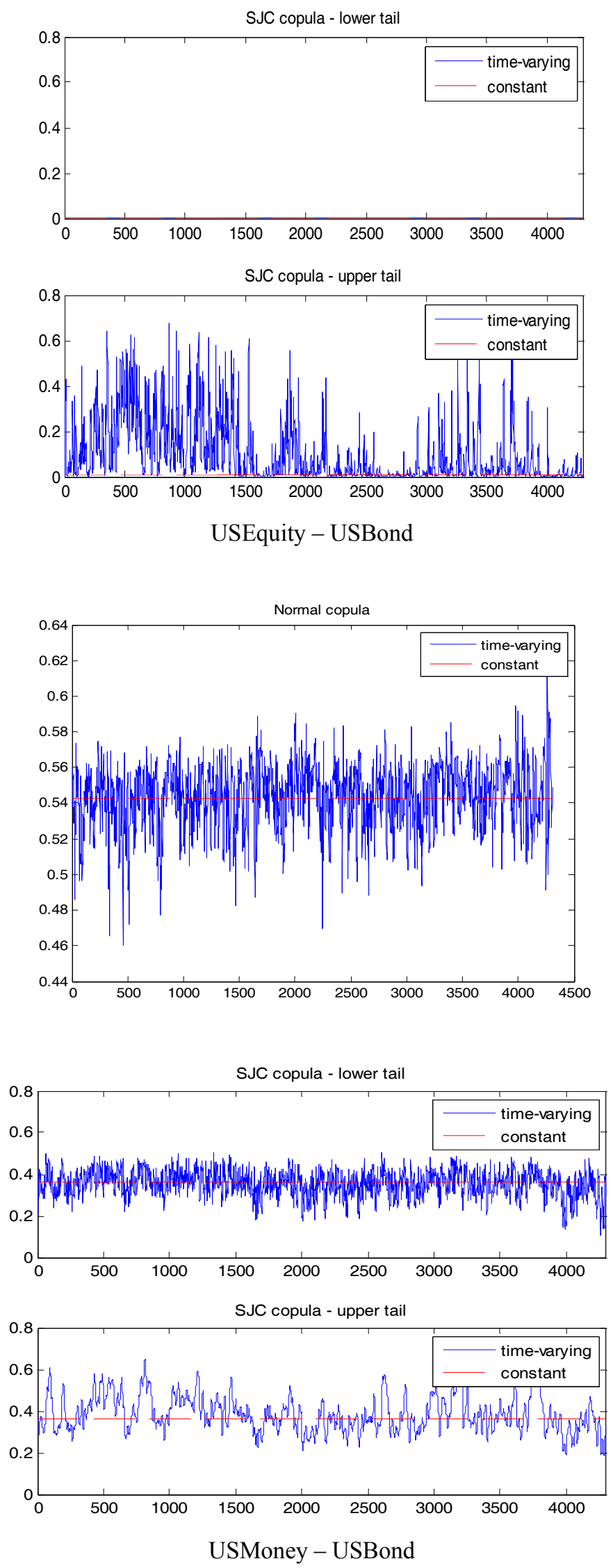

Figure 2. Time-varying copulas for the US markets 
As we can see in Figure 2, the time paths of dependence measure of equity-bond and equity-money pairs seem to be informative for interpretation. The equity-bond pair shows considerably strong positive correlation from 1992 to 1998 , ranging from approximately 0.2 to 0.6 . During the period after 1998 to the end of 2007, its time path is really volatile with a wide interval from -0.5 to 0.55 . However, during 2008 , the range is from -0.6 to -0.2 , implying that these two markets recently have relatively strong negative correlation. Similarly, the dependence measure of the equity-money pair is mainly positive during 1992-1998. It decreased sharply from 0.2 to -0.25 during mid 1997 to early 1998.

After 1998, it peaked at 0.2 around early 2000, at 0.1 twice early 2005 and 2007, and most the rest of the time they had negative dependence. During 2008, the dependence measure hit its lowest point of -0.35 around the mid year, and then climbed up to nearly zero at the end of 2008. The Gaussian copula's time path of dependence measure of the US bond-money pair seems to be uninformative as well as its SJC copula's lower tail time path. However, its SJC copula's upper tail time path is informative with a range from 0.2 to 0.6 during the examined period. It is really volatile within the range and during 2008 it peaked at 0.5 in the middle of the year and then decreased to 0.2 at the end of 2008 .

Additionally, the best copula models for the US equity-bond and equity- money pairs are the time-varying Gaussian copula according to AIC criteria. These markets will go up and down together in the Gaussian copula fashion, and the time-varying copula will help to figure out their time path over time. Similarly, the US bond-money pair shows relatively equal tail dependence, implying that there is an equal possibility that these two markets boom or crash at the same time.

\subsubsection{Cross Countries}

Table 5 reports the estimated results of copulas for the cross-country pairs. In the constant copula case, there are some interesting observations of Gaussian copula in Panel A1 of Table 5. The dependence measures of some market pairs changed their signs from positive to negative after using copula, that is the Australian equity market and the US money market $(0.024$ to -0.02$)$, the Australian bond market and the US equity market $(0.019$ to 0.001 ), and the Australian money market and the US equity market (0.02 to -0.0016). This again may be due to the biasedness of linear correlation with the normality assumption. There is increased dependence measure in the Australian equity market and the US bond market (48\%), the Australian bond market and the US bond market (29\%), and the Australian money market and the US bond market (22\%). Also, there is decreased dependence measure in the Australian equity market and the US equity market (20\%), the Australian bond market and the US money market (71\%), and the Australian money market and the US money market (80\%).

Table 5. Model comparison: constant copulas vs. time varying copulas

\begin{tabular}{lccc}
\hline \multicolumn{1}{c}{ Models } & \multicolumn{2}{c}{$\begin{array}{c}\text { Gaussian copula } \\
\text { Constant }\end{array}$} & \multicolumn{2}{c}{$\begin{array}{c}\text { Symmetrised Joe-Clayton copula } \\
\text { Constant }\end{array}$} & \begin{tabular}{c} 
Time varying \\
\hline AusEquity-AusBond
\end{tabular} \\
AusEquity-AusMoney & $\mathrm{X}^{*}$ & & $\mathrm{X}$ \\
AusBond-AusMoney & $\mathrm{X}^{*}$ & & $\mathrm{X}^{*}$ \\
USEquity-USBond & $\mathrm{X}$ & & $\mathrm{X}$ \\
USEquity-USMoney & $\mathrm{X}^{*}$ & & $\mathrm{X}$ \\
USBond-USMoney & $\mathrm{X}^{*}$ & & $\mathrm{X}^{*}$ \\
AusEquity-USMoney & $\mathrm{X}^{*}$ & & \\
AusEquity-USBond & $\mathrm{X}^{*}$ & $\mathrm{X}$ & \\
AusEquity-USEquity & $\mathrm{X}^{*}$ & $\mathrm{X}$ & \\
AusBond-USMoney & $\mathrm{X}$ & $\mathrm{X}$ & \\
AusBond-USBond & $\mathrm{X}^{*}$ & $\mathrm{X}$ & \\
AusBond-USEquity & $\mathrm{X}^{*}$ & $\mathrm{X}$ & \\
AusMoney-USMoney & $\mathrm{X}^{*}$ & $\mathrm{X}$ & \\
AusMoney-USBond & $\mathrm{X}^{*}$ & $\mathrm{X}$ & \\
AusMoney-USEquity & $\mathrm{X}^{*}$ & $\mathrm{X}$ & \\
\hline
\end{tabular}

Notes: $\mathrm{X}$ is the better between constant and time- varying copulas. * indicates the best fitted model among 4 constant and time varying models. AusEquity, AusBond, and AusMoney are Australian equity, bond, and money market, respectively. USEquity, USBond, and USMoney are the US equity, bond, and money market, respectively. 
The results of the SJC copula in Panel B1 of Table 5 show that the Australian equity market and the US equity market have left tail dependence, implying that there is a tendency that these two markets crash together. The dependence measures of the SJC copula for the other pairs are very tiny, thus considering as no tail dependence. The time-varying copula case is reported in Panels A2 and B2 of Table 5. However, the time paths in this case seem to be uninformative for dependence analysis. We also used AIC criteria to choose the best copula model for the cross-country pairs. The SJC copula is the best model for the joint behavior of the Australian equity market and the US equity market with left tail dependence. And with regard to the other pairs, the time-varying Gaussian copula model best describes the joint behavior of the other pairs, meaning that these market pairs will go either up or down in symmetric normal copula fashion. The result of copula comparison is reported in Table 6.

Table 6. Estimation results for the Australian markets and the US markets

\begin{tabular}{|c|c|c|c|c|c|c|c|c|c|}
\hline & $\begin{array}{l}\text { AusEquity } \\
\text { - USMoney }\end{array}$ & $\begin{array}{l}\text { AusEquity } \\
\text { - USBond }\end{array}$ & $\begin{array}{l}\text { AusEquity } \\
\text { - USEquity }\end{array}$ & $\begin{array}{l}\text { AusBond } \\
\text { - USMoney }\end{array}$ & $\begin{array}{l}\text { AusBond } \\
\text { - USBond }\end{array}$ & $\begin{array}{l}\text { AusBond } \\
\text { - USEquity }\end{array}$ & $\begin{array}{l}\text { AusMoney } \\
\text { - USMoney }\end{array}$ & $\begin{array}{l}\text { AusMoney } \\
\text { - USBond }\end{array}$ & $\begin{array}{l}\text { AusMoney } \\
\text { - USEquity }\end{array}$ \\
\hline \multicolumn{10}{|c|}{ Panel A1: Gaussian copula } \\
\hline$\delta$ & $-0.0205^{*}$ & $-0.0350 * *$ & $0.0562 * *$ & $0.0099 *$ & $-0.0171^{* * *}$ & $-0.0011^{* *}$ & $0.0104 *$ & $-0.0239 * * *$ & $-0.0016^{*}$ \\
\hline Log-L & -0.9007 & -2.6405 & -6.8039 & $-1) .2098$ & -0.6314 & -0.0026 & -0.2327 & -1.2245 & -0.0053 \\
\hline AIC & -1.8010 & -5.2806 & -13.6073 & -10.4191 & -1.2623 & -0.0047 & -0.4650 & -2.4486 & -0.0101 \\
\hline BIC & -1.7996 & -5.2791 & -13.6058 & -10.4176 & -1.2608 & -0.0032 & -0.4635 & -2.4471 & -0.0086 \\
\hline \multicolumn{10}{|c|}{ Panel A2: Time varying Gaussian copula } \\
\hline$\omega$ & $-0.0410^{* *}$ & $-0.0343^{*}$ & $0.0006 * * *$ & $0.0009^{*}$ & $-0.0460^{*}$ & $-0.0120 * *$ & $0.0012 *$ & $-0.0650^{*}$ & $-0.0135^{*}$ \\
\hline$\alpha$ & $0.1346^{*}$ & $-0.0618 * *$ & $0.0045^{* *}$ & $0.0448^{*}$ & $-0.1351^{* *}$ & $0.2003 * *$ & $0.0422 * *$ & $-0.1694^{*}$ & $0.1815^{* *}$ \\
\hline$\beta$ & $0.1499 *$ & $1.1114 * *$ & $1.9889^{*}$ & $1.6542 * * *$ & $-0.5647 * *$ & $-1.8731^{*}$ & $1.6698^{*}$ & $-0.5361 * *$ & $-1.8811 * *$ \\
\hline Log-L & -5.2828 & -3.7399 & -7.9103 & -6.6731 & -1.6220 & -1.6647 & -6.5320 & -2.7696 & -1.4440 \\
\hline AIC & -10.5650 & -7.4793 & -15.8201 & -13.3457 & -3.2434 & -3.3289 & -13.0635 & -5.5387 & -2.8875 \\
\hline BIC & -10.5636 & -7.4778 & -15.8186 & -13.3443 & -3.2420 & -3.3274 & -13.0620 & -5.5372 & -2.8860 \\
\hline \multicolumn{10}{|c|}{ Panel B1: Symmetrised Joe-Clayton copula } \\
\hline$\tau^{\mathrm{U}}$ & $\begin{array}{c}0.9537 \\
\times 1.0 \mathrm{e}-006\end{array}$ & $\begin{array}{c}0.9537 \\
\times 1.0 \mathrm{e}-006\end{array}$ & 0.0000 & $\begin{array}{c}0.9537 \\
\times 1.0 \mathrm{e}-006\end{array}$ & $\begin{array}{c}0.9537 \\
\times 1.0 \mathrm{e}-006\end{array}$ & $\begin{array}{c}0.9537 \\
\times 1.0 \mathrm{e}-006\end{array}$ & $\begin{array}{c}0.9537 \\
\times 1.0 \mathrm{e}-006\end{array}$ & $\begin{array}{c}0.9537 \\
\times 1.0 e-006\end{array}$ & $\begin{array}{c}0.9537 \\
\times 1.0 \mathrm{e}-006\end{array}$ \\
\hline$\tau^{\mathrm{L}}$ & $\begin{array}{c}0.9537 \\
\times 1.0 e-006\end{array}$ & $\begin{array}{c}0.9537 \\
x 1.0 e-006\end{array}$ & $0.0048 * *$ & $\begin{array}{c}0.9537 \\
\times 1.0 e-006\end{array}$ & $\begin{array}{c}0.9537 \\
\times 1.0 e-006\end{array}$ & $\begin{array}{c}0.9537 \\
\times 1.0 \mathrm{e}-006\end{array}$ & $\begin{array}{c}0.9537 \\
\times 1.0 e-006\end{array}$ & $\begin{array}{c}0.9537 \\
\times 1.0 e-006\end{array}$ & $\begin{array}{c}0.9537 \\
\times 1.0 \mathrm{e}-006\end{array}$ \\
\hline Log-L & 3.4589 & 8.2873 & -10.3588 & -1.2558 & 5.1186 & 2.0628 & -1.9299 & 6.1545 & 2.0068 \\
\hline AIC & 6.9183 & 16.5751 & -20.7172 & -2.5112 & 10.2377 & 4.1260 & -3.8593 & 12.3095 & 4.0141 \\
\hline $\mathrm{BIC}$ & 6.9198 & 16.5766 & -20.7157 & -2.5097 & 10.2391 & 4.1275 & -3.8578 & 12.3109 & 4.0156 \\
\hline \multicolumn{10}{|c|}{ Panel B2: Time varying Symmetrised Joe-Clayton copula } \\
\hline$\omega^{\mathrm{U}}$ (upper tail) & $-13.8648^{*}$ & $-13.8657^{*}$ & $-20.1658 *$ & $-13.8640^{* *}$ & $-13.8649 *$ & $-13.8650 * *$ & $-13.8640^{*}$ & $-13.8651 * *$ & $-13.8650 *$ \\
\hline$\alpha^{\mathrm{U}}$ & $-0.0008 * *$ & $-0.0010^{* * *}$ & -0.0000 & $-0.0004^{* * *}$ & $-0.0006^{* * *}$ & $-0.0007 * * *$ & $-0.0004^{* * *}$ & $-0.0007 *$ & $-0.0007 *$ \\
\hline$\beta^{\mathrm{U}}$ & 0.0000 & 0.0000 & 0.0000 & 0.0000 & 0.0000 & 0.0000 & 0.0000 & 0.0000 & 0.0000 \\
\hline$\omega^{\mathrm{L}}$ (lower tail) & $-13.8649 *$ & $-13.8652^{*}$ & $-7.1953 * *$ & $-13.8644^{* *}$ & $-13.8650^{* *}$ & $-13.8642^{*}$ & $-13.8642 *$ & $-13.8652^{*}$ & $-13.8642 * *$ \\
\hline$\alpha^{L}$ & $-0.0007 * *$ & $-0.0008^{* * *}$ & $-0.8967 * *$ & $-0.0005^{* * *}$ & $-0.0007^{* * *}$ & $-0.0004 * *$ & $-0.0005^{*}$ & $-0.0007^{*}$ & $-0.0004 *$ \\
\hline$\beta^{\mathrm{L}}$ & 0.0000 & 0.0000 & $-0.0071^{* * *}$ & 0.0000 & 0.0000 & 0.0000 & 0.0000 & 0.0000 & 0.0000 \\
\hline Log-L & 13.8279 & 22.9204 & -6.4792 & 4.4365 & 16.5898 & 10.6797 & 3.2838 & 18.6286 & 10.6067 \\
\hline AIC & 27.6563 & 45.8412 & 12.9579 & 8.8735 & 33.1800 & 21.3598 & 6.5680 & 37.2577 & 21.2139 \\
\hline $\mathrm{BIC}$ & 27.6578 & 45.8427 & -12.9564 & 8.8750 & 33.1815 & 21.3613 & 6.5695 & 37.2591 & 21.2154 \\
\hline
\end{tabular}

Notes: Log-L: Log Likelihood. AusEquity, AusBond, and AusMoney are Australian equity, bond, and money market, respectively. USEquity, USBond, and USMoney are the US equity, bond, and money market, respectively. *, **, *** denote significance at $10 \%, 5 \%, 1 \%$, respectively.

\section{Concluding Remarks}

This paper investigated the dependence structure between the equity, bond and money markets in Australia, the US and across the two countries. It proposes the combination of the empirical distribution for marginal distributions and time-varying copula models for the joint distributions between the markets. The paper showed that the method is effective in analyzing dependence structure among the markets.

Our findings indicate that the time-varying SJC copula is the best model for the joint behavior of the Australian bond-money market pair and the US bond-money market pair during the examined period, meaning that these pairs exhibit both right and left tail dependence in extreme market events. And the SJC copula is the best fit for the pair of Australian equity market and the US equity market with left tail dependence and without right tail dependence. This implies that these two markets are likely to go down together during the period of negative extreme events. The rest of the pairs follow the pattern of the time-varying Normal copula, which means these pairs boom and crash together in a symmetric fashion. And also, the paper's findings underline the importance of analyzing dependence structure across financial markets and, on top of that, would be useful for portfolio managers, derivative dealers and any investors who want to reduce losses or seek portfolio diversification benefits within the equity, bond and money markets in Australia, the US and across these two countries. Last but not least, copula models prove to be an informative, flexible and effective method improving our understanding 
of the market dependence.

\section{References}

Aldel, B., \& Salma, J. (2012). The Greek financial market, extreme co-movements and contagion effects in the EMU: A copula approach. International Journal of Accounting and Financial Report, 2(1), 289-307. http://dx.doi.org/10.5296/ijafr.v2i1.1952

Andersen, T. G., Bollerslev, T., Diebold, F. X., \& Vega, C. (2007). Real-time price discovery in global stock, bond and foreign exchange markets. Journal of International Economics, 73, 251-227. http://dx.doi.org/10.1016/j.jinteco.2007.02.004

Ane, T., \& Kharoubi, C. (2003). Dependence structure and risk measure. Journal of Business, 76(3). http://dx.doi.org/10.1086/375253

Brailsford, T., Frino, A., Hodgson, A., \& West, A. (1997). Stock market automation and the transmission of information between spot and futures markets. Working Paper Series: University of Sydney.

Chen, X., \& Fan, Y. (2005). Pseudo-likelihood ratio tests for semi-parametric multivariate copula model selection. Canadian Journal of Statistics, 33, 389-141. http://dx.doi.org/10.1002/cjs.5540330306

Choudhury, M. A., \& Bhatti, M. I. (2006). Learning financial volatility. International Journal of Business and Economic Research, 4(2), 165-174.

Ehrmann, M., Fratscher, M., \& Rigobon, R. (2011). Stocks, bonds, money markets and exchange rates: Measuring international financial transmission. Journal of Applied Econometrics, 26(6), 948-974. http://dx.doi.org/10.1002/jae.1173

Embrecht, P., McNeil, A., \& Straumann, D. (1999). Correlation and dependency in risk management: Properties and pitfalls. Working paper: Department of Mathematics, ETHZ, Zurich.

Engle, R. (2002). Dynamic conditional correlation: A simple class of multivariate GARCH models. Journal of Business and Economics Studies, 20, 339-350. http://dx.doi.org/10.1198/073500102288618487

Engle, R. (2001). GARCH 101: The use of ARCH/GARCH models in applied econometrics. Journal of Economic Perspectives, 15(4), 157-168. http://dx.doi.org/10.1257/jep.15.4.157

Fermanian, J. D. (2005). Goodness of fit tests for copulas. Journal of Multivariate Analysis, 95, 119-152. http://dx.doi.org/10.1016/j.jmva.2004.07.004

Fleischer, P. (2003). Volatility and information linkages across markets and countries. Australian Journal of Management, 28(3), 251-272. http://dx.doi.org/10.1177/031289620302800302

Fleming, J., Kirby, C., \& Ostdiek, B. (1998). Information and volatility linkages in the stock, bond and money markets. Journal of Financial Economics, 49, 111-137. http://dx.doi.org/10.1016/S0304-405X(98)00019-1

Floros, C. (2008). Modelling volatility using GARCH models: Evidence from Egypt and Israel. Middle Eastern Finance and Economics, 2, 31-41. http://dx.doi.org/10.5539/ijef.v4n8p161

Frees, E. W., \& Valdez, E. (1998). Understanding relationships using copulas. North American Actuarial Journal, 2(1), 1-25. http://dx.doi.org/10.1080/10920277.1998.10595667

Genest, C., Quessy, J., \& Remillard, B. (2006). Goodness of fit test procedures for copula models based on the probability integral transformation. Scadinavian Journal of Statistics, 33, 337-366. http://dx.doi.org/10.1111/j.1467-9469.2006.00470.x

Hans, M. (2007). Estimation and model selection of copulas with an application to exchange rate. Working paper series: Maastricht research school of economics of technology and organizations.

$\mathrm{Hu}$, L. (2006). Dependence patterns across financial markets: a mixed copula approach. Applied Financial Economics, 16, 717-729. http://dx.doi.org/10.1080/09603100500426515

Joe, H., \& Xu, J. (1996). The estimation method of inference functions for margins for multivariate models. Technical report No. 166: Department of statistics, University of British Columbia, Vancouver.

Joe, H. (1997). Multivariate models and dependence concepts. Chapman \& Hall, London. http://dx.doi.org/10.1201/b13150

Kim, S., In, F., \& Viney, C. (2001). Modelling linkages between Australian financial futures markets. Australian Journal of Management, 26, 1-11. http://dx.doi.org/10.1177/031289620102600102

Li, F. (2010). Identifying of asymmetric comovements of international stock market returns. Working paper 2010-21, 
Bank of Canada. Retrieved from http://www.bankofcanada.ca/wp-content/uploads/2010/08/wp10-21.pdf

Nelsen, R. B. (1991). Conditional heteroscedasticity in asset returns: A new approach. Econometrica, 59, 347371. http://dx.doi.org/10.2307/2938260

Nelsen, R. B. (2006). An Introduction to Copulas. New York: Springer-Verlag.

Nguyen, C., \& Ishaq, B. M. (2012). Diversification evidence from international equity markets using extreme values and stochastic copulas. Journal of International Financial Markets, Institutions \& Money, 22(3), 622-646. http://dx.doi.org/10.1016/j.intfin.2012.02.004

Patton, A. J. (2006). Modelling asymmetric exchange rate dependence. International Economics Review, 47(2), 527-556. http://dx.doi.org/10.1111/j.1468-2354.2006.00387.x

Turgutlu, E., \& Ucer, B. (2007). Is global diversification rational? Evidence from emerging equity markets through mixed copula approach. Applied Economics, 1-12. http://dx.doi.org/10.1080/00036840701704485

Wang, K. (2009). Volatility linkages of the equity, bond and money markets: An implied volatility approach. Accounting and Finance, 49, 207-219. http://dx.doi.org/10.1111/j.1467-629X.2008.00281.x

Wang, K. (2010). Forecasting volatilities in equity, bond and money markets: A market-based approach. Australian Journal of Management, 35(2), 165-180. http://dx.doi.org/10.1177/0312896210370080

\section{Copyrights}

Copyright for this article is retained by the author(s), with first publication rights granted to the journal.

This is an open-access article distributed under the terms and conditions of the Creative Commons Attribution license (http://creativecommons.org/licenses/by/3.0/). 